\title{
Mechanisms and Effective Prevention of Damage for Formations with Low-Porosity and Low-Permeability
}

\author{
Jienian Yan and Jiaojiao Geng \\ China University of Petroleum, Beijing \\ China
}

\section{Introduction}

With the progress of the petroleum industry and the increased demands of the oil and gas resources, the focus of petroleum exploration and development has been shifted from the formations with high permeability to the ones with low-porosity and low-permeability all over the world. As a newly emerging force to increase the oil and gas reserves and energy supplies, the development of the formations with low-porosity and low-permeability has provided significant potential for the steady development of the petroleum industry. Since the 1990s', the reserves of this type of reservoir have occupied a large percentage of the total reserves, which has already reached up to $60 \%$ to $70 \%$ according to statistical data, with an accumulative total of 4.349 billion ton, distributing extensively in 21 blocks of the major oilfields in China.

Due to the already inherently low permeability, and to the fact that the reservoirs with lowporosity and low-permeability are commonly characterized by the tiny size of the pore throats, high content of clay minerals, high capillary pressure and high flow-resistance, this type of reservoir is susceptible to formation damage that is difficult to remove and easy to result in the loss of the industrial capacity, compared with the conventional reservoirs. Therefore, the mechanisms and effective prevention of damage for target formations with low-porosity and low-permeability have attracted high attention in petroleum engineering and have important significance for the increase in reserves and production. So far, the conventional techniques and methods which are only applicable to higher permeability formations have been still adopted for the formation damage control of this type of reservoir, and there is no systematic and deep-going research on this subject.

This chapter provides a summary of recent work which has been conducted in the analysis of formation damage associated with the formations with low-porosity and lowpermeability. Although little solid invasion has been observed in formations with lowpermeability, the invasion of filtrates of drilling fluids often induces the damage of various kinds of sensitivities easily, especially the water-sensitivity damage caused by clay swelling. Also, water blocking is one of the most common mechanisms of damage for formations with low-porosity and low-permeability. This phenomenon has been observed as a particularly severe problem in reservoirs with ultra-low permeability or where the original water saturation is lower than the irreducible water saturation formed by the invasion fluids. 
Numerous studies have shown that the damage induced by water-blocking may decrease the effective permeability to oil by $70 \%$ to $90 \%$.

Generally, the permeability is usually too low to be carried out the core flooding tests easily for the formations with low-permeability. Sometimes it is difficult for the engineers to retrieve typical core samples and conduct detailed evaluation tests. Hence, it is significant to establish the mathematical models for predicting the mechanisms of formation damage for this type of reservoir. The new mathematical models were developed to predict the five kinds of sensitivities of formations and the damage induced by water blocking quantitatively in this study on the basis of numerous experimental results, applying the theory of petrophysics and interfacial chemistry for reservoirs and the intelligent method of ANN (Artificial Neural Network). Extensive applications have shown that more than $85 \%$ of the predicting results are in agreement with the experimental results.

From the aspect of drilling fluids, the effective techniques of prevention for the formations with low-porosity and low-permeability have been proposed as follows: (1) The inhibition of drilling fluids should be enhanced in order to reduce the formation sensitivity; (2) Effecient surfactants should be optimized so as to reduce the oil/water interfacial tension, and minimize formation damage induced by water blocking; (3) Adopt the technique of ideal packing compounding with film-forming to form quickly ultra-low permeable mud cake so as to minimize the filtrate of drilling fluids; (4) All kinds of treating agents used in drilling fluids should be compatible with formation rocks and fluid.

Specific successful application of the drilling fluid systems suitable for protecting the reservoirs with low-porosity and low-permeability used in a certain oilfield is presented in this paper, which can improve the returned permeability of core samples to more than $85 \%$ and enhance productivity considerably.

\section{Damage mechanisms of formations with low-porosity and low-permeability}

\subsection{Solid invasion and fines migration}

Since the pore size is approximately in a direct proportion to the permeability, the pores of which the size is smaller than $1 \mu \mathrm{m}$, occupy as much as $35 \%-90 \%$ in formations with lowporosity and low-permeability; while there are nearly no solid particles with the size smaller than $2 \mu \mathrm{m}$ in the current drilling fluid systems. Therefore, the majority solid particles (bentonite, barite, bridging agents, drilling cuttings, etc.) in drilling fluids are too large to invade into the formations. Even if there is a little solid phase invasion, the perforation will be eliminate the corresponding damage (Bennion, D., 2000). On the other hand, the mobile fines are capsuled by the still water, namely, the wetting phase in the formations with lowporosity and low-permeability, which isolates the particles from the flowing oil and gas. In addition, there are only relatively few mobile fines present in pores and throats since this type of formation often buried deeply and accompanied by the compaction and diagenesis. Hence, the solid phase invasion and fines migration are usually not the main mechanisms of damage in this type of formation.

\subsection{Formation sensitivity}

Although little solid invasion has been observed in formations with low-permeability, the invasion of filtrates of drilling fluids often induces the damage of various kinds of sensitivities easily, especially the water-sensitivity damage caused by clay swelling. Usually, there is high 
content of active clay minerals, such as smectite and mixed layer of illite/smectite that can react with the filtrate of water-based fluids in the formations with low-porosity and lowpermeability. Expandable clays can swell 600 to 1000 times their original volume after exposure to incompatible fluids, expanding to plug pores and pore throats, reducing permeability of formations drastically and leading to formation damage (Brian, D., 2004, Erwom, M.D., 2003, Bennion, D., 2002). The fines generated during swelling can also migrate and plug at pore throats, reducing permeability further. Hence, it is important to enhance the inhibition of drilling fluid and make sure that the drilling fluids are compatible with formation rock and fluid so as to minimize the damage of formation sensitivity.

\subsection{Water blocking}

Water blocking, which has been discussed extensively in the literature from both a theoretical and field production perspective, is one of the most common mechanisms of damage for formations with low-porosity and low-permeability, and the damage induced by water-blocking may decrease the effective permeability to oil by $70 \%$ to $90 \%$ (Shu Y., 2009, Geng J.J., 2010, Zhang H.X., 2010). The water blocking occurs due to the capillary effect of micro-pores for this type of formation when the filtrate of drilling fluids invades formation, as shown in Fig.1. The capillary force can be expressed by the Laplace's equation:

$$
\Delta \mathrm{P}=2 \sigma\left(\frac{1}{R_{1}}-\frac{1}{R_{2}}\right)
$$

Where, the $\Delta \mathrm{P}$ is the differential pressure of the surface; $\mathrm{\sigma}$ is the oil/water interfacial tension; and $R_{1}, R_{2}$ is the radius of the two surfaces, respectively.

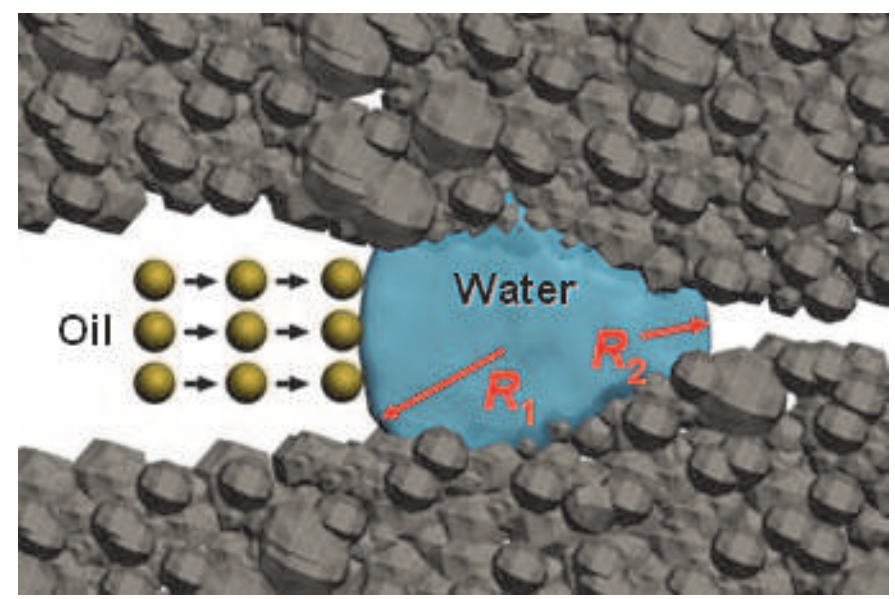

Fig. 1. Schematic diagram for water blocking effect

In the formations with low-porosity and low-permeability, originally, water usually adsorbs on the surface of water-wet rocks or occupies at the corner of micro-pores, while the oil and gas are in the middle areas and afford the flow passage. As the invasion of well fluids, the water content in the pore structure increases sharply due to the capillary effect of micropores. Then the water blocking occurs and the number of the flow passage has been 
reduced. This phenomenon has been observed as a particularly severe problem in reservoirs with ultra-low permeability $\left(1 \times 10^{-3} \mu \mathrm{m}^{2} \sim 0.1 \times 10^{-3} \mu \mathrm{m}^{2}\right)$ or where the initial water saturation $\left(S_{w i}\right)$ is lower than the irreducible water saturation $\left(S_{w i r r}\right)$ formed by the invasion fluids. As shown in Fig. 2, when the $S_{w i}$ is lower than the $S_{w i r r}$ which is obtained from a conventional water-gas drainage capillary pressure test, the water blocking occurs inevitably. The larger the difference between the $S_{w i}$ and $S_{w i r r}$ is, the greater the decline of permeability is, and the more severity the formation damage is.

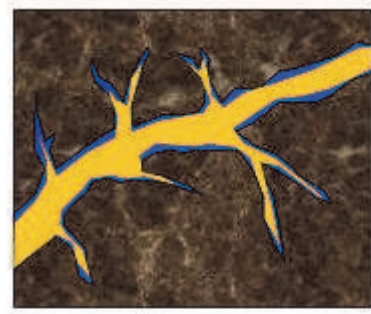

Initial Status

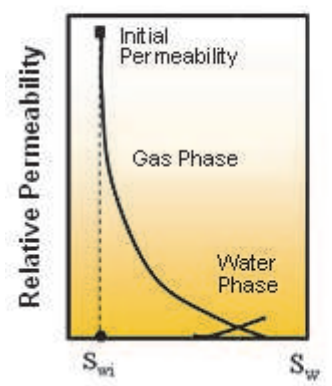

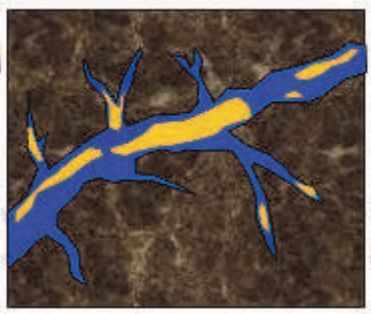

External Fluid Invasion

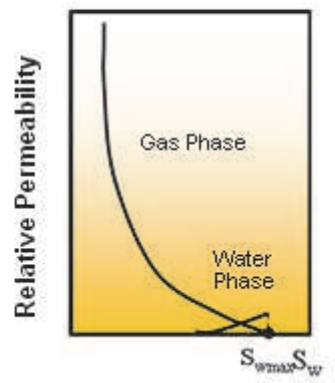

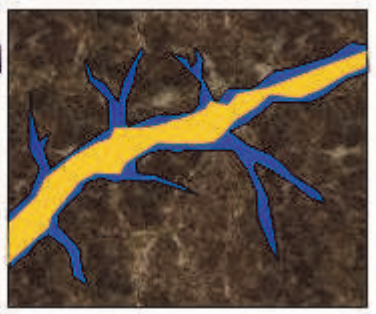

After Displacement

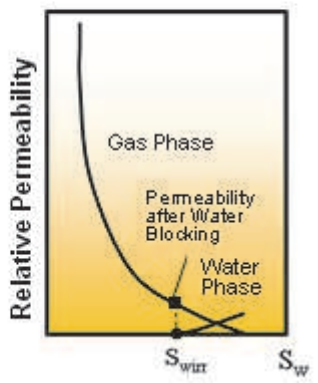

Fig. 2. Changes of relative permeability of water-gas

\begin{tabular}{|c|c|c|c|c|c|}
\hline \multirow{2}{*}{ 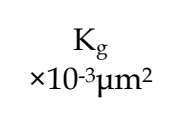 } & \multicolumn{5}{|c|}{ Damage degree of water blocking $\left(\mathrm{R}_{\mathrm{s}}\right)$} \\
\hline & $\begin{array}{c}S_{\mathrm{wi}} \\
<10 \%\end{array}$ & $\begin{array}{c}S_{\mathrm{wi}} \\
10-20 \%\end{array}$ & $\begin{array}{c}S_{\mathrm{wi}} \\
20-30 \%\end{array}$ & $\begin{array}{c}S_{\mathrm{wi}} \\
30-50 \%\end{array}$ & $\begin{aligned} & S_{w i} \\
> & 50 \%\end{aligned}$ \\
\hline $\mathrm{K}_{\mathrm{g}}<0.1$ & Severe & Severe & Moderate & Moderate & Weak \\
\hline $0.1<\mathrm{K}_{\mathrm{g}}<1$ & Severe & Moderate & Weak & Weak & Weaker \\
\hline $1<\mathrm{K}_{\mathrm{g}}<10$ & Severe & Moderate & Weak & Weaker & No damage \\
\hline $10<\mathrm{K}_{\mathrm{g}}<100$ & Moderate & Weak & Weaker & No damage & No damage \\
\hline $100<\mathrm{K}_{\mathrm{g}}<500$ & Weak & Weak & No damage & No damage & No damage \\
\hline $\mathrm{K}_{\mathrm{g}}>500$ & Weaker & No damage & No damage & No damage & No damage \\
\hline
\end{tabular}

Table 1. Correlation between water blocking effect and the $K_{g} / S_{w i}$

Note: Severe- $R_{s}>90 \%$; Moderate-50 \% $<R_{s} \leq 90 \%$; Weak-20 \% $<R_{s} \leq 50 \%$; Weaker-10 \% $<R_{s}$ $\leq 20 \%$; No damage- $R_{s} \leq 10 \%$.

The severity of water blocking is highly influenced by: (1) initial fluid saturations in the reservoir, (2) rock wettability, (3) pore system geometry, (4) fluid type, composition and interfacial tension, (6) invasion depth of fluid into formation. It can be seen from the 
statistics results shown in Table 1 that the lower the permeability to gas $\left(K_{g}\right)$ and the $S_{w i}$ are, the more serious the water blocking phenomenon is; while the permeability is higher than $100 \times 10^{-3} \mu^{2}$, there will be no water blocking. Since the inherent properties can not be changed, to alleviate water blocking effect, the filtration loss of drilling fluids should be controlled as low as possible. Meanwhile, adding some surfactants or alcohols in drilling fluids is quite helpful to minimize the oil/water interfacial tension, and then reduce the capillary resistance and prevent damage induced by water blocking.

\section{Prediction of formation sensitivities}

So far, the conventional techniques and methods which are only applicable to higher permeability formations have been still adopted for the evaluation of formation damage degree of this type of reservoir. However, the permeability is usually too low to be carried out the core flooding tests easily for the formations with low-permeability. And sometimes it is difficult for the engineers to retrieve typical core samples and conduct detailed evaluation tests. Hence, it is significant to establish mathematical models for predicting the mechanisms of formation damage for this type of reservoir.

\subsection{Comparison and selection of the predicting method}

The five sensitivities of formations include the sensitivity to flow rate, to water, to salinity, to alkalinity and to acidity. These sensitivities are influenced by various factors which interact on each other complexly. From the aspect of lithology and physical property analysis, a considerable effort has been made to explain and evaluate the damaging extent of formation sensitivities. However, it is very difficult to establish a specific structural model between formation sensitivities and influencing factors according to the principle of chemical balance. So far, a number of mathematical models have been established to predict formation sensitivities, such as Multigroup Discriminant Analysis (MDA), Multiple Regression Analysis (MRA) and Fuzz Mathematical (FM).

The MDA method is to divide the known core samples into several groups and build the discriminant function of the formation sensitivity degree and the parameters of core samples for each group. Then by putting the parameters of the unknown samples into the corresponding function, the formation sensitivity degree will be judged. Although the predicting result is objective, the MDA only generates qualitative results, which is wide of the truth and very difficult to use in practice.

The MRA method is assumed firstly that there is a certain function between the formation sensitivity degree and the parameters of the core sample. Then the undetermined coefficient and the regression equation are obtained by regressing the known samples. It is very convenient to evaluate the formation sensitivity degree by substituting the parameters of the unknown sample into the regression equation. However, the MRA depends on human factors, and there will be a big error if the regression equation selected is not proper.

The FM method adopts the inverse problem of synthetic judgment in fuzzy mathematics to solve the fuzzy relationship between the influencing factors and the formation damage degree which is only suitable for the simple case. Due to the various influencing factors and the complex reaction in this situation, the FM exhibits low efficiency.

We can see that methods discussed above are not accurate enough to predict the formation sensitivity. The Artificial Neural Networks (ANN) method has been increasingly used for prediction of complexes non-linear systems with good precision (Kalam, M.Z., 1996; 
Nikravesh, M., 1996; Zuluaga, E., 2000). The ability of ANN systems is to spontaneously learn from examples, reason over inexact and fuzzy data, and provide adequate responses to new information not previously seen. It consists of a large number of simple interconnected artificial neurons. As shown in Fig.3, the artificial neuron (i) takes information from other neurons $\left(x_{1}, x_{2}, x_{3} \ldots x_{\mathrm{n}}\right)$, performs very simple operations on this data, and passes results $\left(y_{i}\right)$ on to other artificial neurons. Every artificial neuron meets the following equations:

$$
\begin{gathered}
\mathrm{s}_{i}=\sum_{j=1}^{n} w_{j} x_{j}-\theta_{i} \\
u_{i}=g\left(s_{i}\right) \\
y_{i}=f\left(u_{i}\right)
\end{gathered}
$$

Where, equation (2) is the accumulating potential value of the artificial neuron (i) after synapse; $\theta_{i}$ is the processing elements threshold; and $w_{i}$ is the interlayer connection weights. Equation (4) is the relational expression between input and output values, in which $u_{i}$ is the state of the artificial neuron (i). Neural networks operate by virtue of many artificial neuron data in this manner.

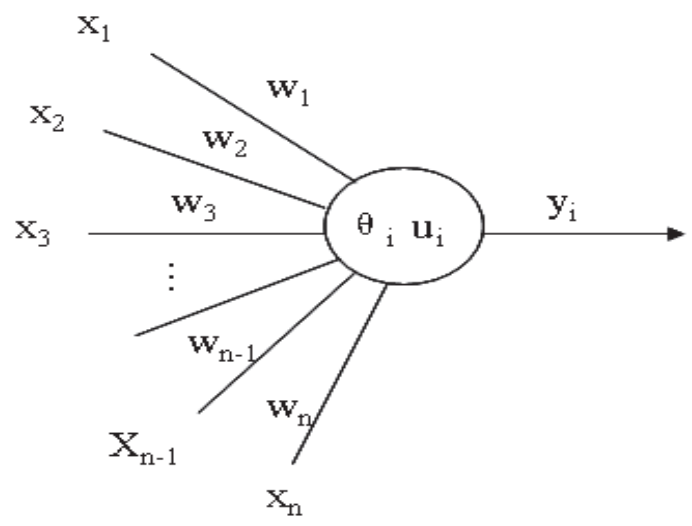

Fig. 3. Sketch Diagram of Artificial Neuron

The specific operation has two steps. One is the training process and another is the testing process. In the process of training, the ANN model has to be trained to recognize the relationships between the input and the desired output values by adjusting the connection weights between the different neurons. This process continues until weights converge to the desired error level or the output reaches an acceptable level. In the testing process, the developed ANN model is tested with several sets of experimental values, which are not used in the training of the model, to judge its performance. The developed model can memorize the correct output once input data is given. Compared with other methods, the ANN method has many advantages and has been introduced to predict the formation sensitivity. 


\subsection{Development of the predicting model}

Determinate the influencing factors of formation sensitivities. As we all know, the formation sensitivity depends on many factors, such as the rock structure, the composition of the formation, the formation fluid, etc. Based on the theoretical analysis and experimental study, the influencing factors have been determined. Take the water-sensitivity damage as an example, the mainly influencing factors are shale content, smectite content, illite content, illite/smectite content, illite/bentonite ratio, porosity, permeability, cemented type, mineral size, and salinity.

Collect and process the data. The data in ANN model can be divided into qualitative data and quantitative data. In order to meet the requirements of the model, the qualitative data must be quantified firstly, and then all the data must be normalized. The examples are presented.

(1) The particle sorting

Generally, the sorting coefficient of rock is expressed by Fowke Watder's Standard Deviation, the normalization is as followed:

$$
X_{i}=\left\{\begin{array}{l}
0.0690 \delta_{i}<0.35 \\
\delta_{i} /(4.0+3.5) 0.35 \leq \delta_{i} \leq 4.0 \\
0.9432 \delta_{i}>4.0
\end{array}\right.
$$

where $X_{\mathrm{i}}$ is the normalized value; $\delta_{\mathrm{i}}$ is the Fowke Warder Standard Deviation.

(2) The normalization of the contents of smectite and illite/ smectite

$$
\begin{aligned}
& X_{i}=1.0-\exp \left(-0.6701 S_{i}\right) \\
& S_{i}=M_{i}+0.6 I_{i}
\end{aligned}
$$

where $M_{\mathrm{i}}$ is the content of smectite, $\%$; $I_{\mathrm{i}}$ is the content of illite, $\%$; $X_{\mathrm{i}}$ is the normalized value.

(3) The evaluation criteria of water sensitivity

According to the standard of core flooding experiment SY/Y5358-2002, the criteria are shown in Table 2.

\begin{tabular}{|c|c|}
\hline Degree of Water Sensitivity & Water Sensitivity Index $\left(\boldsymbol{I}_{\boldsymbol{w}}\right)$ \\
\hline No sensitivity & $I_{w} \leq 0.05$ \\
\hline Weak & $0.05<I_{w} \leq 0.30$ \\
\hline Intermediate-weak & $0.30<I_{w} \leq 0.50$ \\
\hline Intermediate-strong & $0.50<I_{w} \leq 0.70$ \\
\hline Strong & $0.70<I_{w} \leq 0.90$ \\
\hline Very strong & $I_{w}>0.90$ \\
\hline
\end{tabular}

Table 2. Evaluation Criteria of Water Sensitivity

Select and modify the algorithm. The standard BP (Back Propagation) model is one of the ANN models that consists of a three-layer neurons, an input layer, an output layer and a hidden layer, and it is usually used in formation sensitivity prediction. Although the BP algorithm is valid in the standard $\mathrm{BP}$ model, there are some problems in adjusting the interlayer connection weights, such as the low learning speed, likely to converge to a local minimum point, etc. Hence, the modified BP algorithm has been developed by the use of appending momentum factors, adjusting automatically learning factors and batch 
processing of connection weights adjustment, which proved to be more effective. Finally, the model for predicting the formation sensitivities has been established by using the modified BP algorithm in this study.

\subsection{Application of the predicting model}

Based on the ANN model established above, the practical software has been developed using the Visual Basic for Windows 6.0. It is very convenient for use in the field only by inputting the related parameters of formations and obtaining the indices of the formation sensitivities automatically, which can be instead of the complicated and time-consuming laboratory tests. The accuracy of the predictions can be significantly enhanced with model training using more precise reservoir data in the field applications. Neural networks have immense potential in predicting sensitivities and thereby assessing formation damage in reservoirs. The software has been tested using the production data. As shown in Table 3, more than $85 \%$ of the predicting results are in agreement with the experimental results.

\begin{tabular}{|c|c|c|c|c|c|c|c|c|c|c|c|c|}
\hline $\begin{array}{l}\text { Core } \\
\text { No. }\end{array}$ & $\begin{array}{c}\text { Shale } \\
\%\end{array}$ & $\begin{array}{c}\text { Quartz } \\
\%\end{array}$ & $\begin{array}{c}\text { Smectite } \\
\%\end{array}$ & I/S \% & $\begin{array}{c}\text { I/S } \\
\text { Ratio } \\
\%\end{array}$ & $\begin{array}{c}\text { Particle } \\
\text { Size } \\
\text { AVG } \%\end{array}$ & $\begin{array}{c}\text { Porosity } \\
\%\end{array}$ & $\begin{array}{c}\mathrm{Kg} \mathrm{10} \\
{ }^{3} \mathrm{\mu m}^{2}\end{array}$ & $\begin{array}{c}\text { Salinity } \\
\mathrm{g} / \mathrm{L}\end{array}$ & $\begin{array}{l}\text { Cementa- } \\
\text { tion Type }\end{array}$ & $\begin{array}{c}\text { Predicting } \\
\text { Index }\end{array}$ & $\begin{array}{c}\text { Test } \\
\text { Index }\end{array}$ \\
\hline 2 & 5.21 & 25 & 0.10 & 2.86 & 25 & 0.132 & 14.5 & 1.46 & 10.57 & Contact & 0.316 & 0.315 \\
\hline 3 & 4.74 & 45 & 0.40 & 0.00 & 0 & 0.168 & 15.4 & 14.2 & 3.95 & Porosity & 0.425 & 0.457 \\
\hline 6 & 7.72 & 40 & 0.12 & 5.56 & 20 & 0.150 & 24.5 & 7.06 & 5.00 & Contact & 0.502 & 0.500 \\
\hline 7 & 2.94 & 40 & 0.45 & 0.71 & 30 & 0.175 & 16.6 & 41.6 & 6.72 & $\begin{array}{l}\text { Contact- } \\
\text { porosity }\end{array}$ & 0.539 & 0.531 \\
\hline 9 & 5.00 & 40 & 0.00 & 0.75 & 40 & 0.500 & 8.37 & 2.80 & 7.26 & Porosity & 0.326 & 0.323 \\
\hline 11 & 9.45 & 30 & 1.40 & 6.80 & 30 & 0.120 & 21.1 & 37.1 & 5.00 & $\begin{array}{l}\text { Contact- } \\
\text { porosity }\end{array}$ & 0.717 & 0.743 \\
\hline 34 & 5.08 & 46 & 0.72 & 2.03 & 25 & 0.149 & 14.7 & 23.1 & 3.95 & $\begin{array}{l}\text { Contact- } \\
\text { porosity }\end{array}$ & 0.611 & 0.588 \\
\hline 56 & 3.78 & 40 & 0.80 & 1.51 & 25 & 0.179 & 15.6 & 43.4 & 3.95 & $\begin{array}{l}\text { Contact- } \\
\text { porosity }\end{array}$ & 0.637 & 0.635 \\
\hline
\end{tabular}

Table 3. Partial Results of Water Sensitivity Prediction

\section{Evaluation and prediction of water blocking}

\subsection{Evaluation of water blocking}

Water blocking has been recognized as one of the major causes of formation damage for the sandstone reservoirs with low-permeability, which may result in tremendous productivity reduction. Because of the complexity and variability of the pore structures, it is difficult to calculate the capillary force by using the Laplace's equation, and then judge the extent of damage induced by water blocking. Hence the experimental study on the formation damage induced by water blocking has been conducted in the laboratory.

In order to remove the interference, a certain amount of core samples with no or minor formation sensitivity, taken from the typical formations with low-porosity and lowpermeability, have been chosen for the evaluation tests. The testing procedure was as follows: Firstly, the permeability to nitrogen gas was measured by using dry core, and the cores were vacuum saturated by standard brine, then the cores was displaced with kerosene to leaving irreducible water remaining in the core, and then core permeability was measured by displacing with kerosene in the forward direction after it was contaminated by 
brine in the reverse direction. Finally the rate of permeability damage was calculated. The intelligent core flooding apparatus was used for displacement tests, while the the oil/water interfacial tension was measured by using XZD-3 entire measuring range tension apparatus. It can be seen from the test results shown in Table 4 that the extent of damage induced by water blocking is not only related to permeability, but also related to the initial water saturation, porosity, oil/water interfacial tension, etc. As a general rule, the lower the permeability or the higher the interface tension is, the more serious water blocking will happen. This rule is summarized by assuming that the other influencing factors kept constant when the influence of an individual factor was considered. However, there will be a dimly defined relationship between water blocking and each influencing factor if a variety of factors are changing at the same time. In order to achieve the quantitative prediction of water blocking in formations with low-porosity and low-permeability, it is essential to develop the mathematical model of the damage extent induced by water blocking and the influencing factors, by using the experimental data.

\begin{tabular}{|c|c|c|c|c|c|c|}
\hline $\begin{array}{c}\boldsymbol{K}_{\mathbf{g}} \\
\mathbf{1 0}^{-3} \mathbf{\mu m}^{\mathbf{2}}\end{array}$ & $\begin{array}{c}\boldsymbol{\varphi} \\
\mathbf{\%}\end{array}$ & $\begin{array}{c}\boldsymbol{S}_{w i} \\
\mathbf{\%}\end{array}$ & $\begin{array}{c}\mathbf{\sigma} \\
\mathbf{m N} / \mathbf{m}\end{array}$ & $\begin{array}{c}\mathbf{K}_{\mathbf{o}} \\
\mathbf{1 0}^{-3} \boldsymbol{\mu m}^{\mathbf{2}}\end{array}$ & $\begin{array}{c}\mathbf{K}_{\mathbf{o a}} \\
\mathbf{1 0}^{-3} \boldsymbol{\mu m}^{\mathbf{2}}\end{array}$ & $\begin{array}{c}\boldsymbol{R}_{\mathbf{s}} \\
\mathbf{\%}\end{array}$ \\
\hline 11.96 & 16.8 & 49.29 & 2.081 & 8.64 & 4.32 & 50.00 \\
\hline 6.78 & 9.34 & 14.75 & 2.081 & 4.90 & 2.53 & 48.32 \\
\hline 19.86 & 9.16 & 65.84 & 0.868 & 15.51 & 13.01 & 16.12 \\
\hline 26.81 & 14.8 & 40.02 & 0.652 & 19.37 & 17.43 & 9.99 \\
\hline 9.22 & 22.2 & 51.79 & 0.469 & 5.43 & 4.38 & 19.34 \\
\hline 4.67 & 16.0 & 38.95 & 0.360 & 3.85 & 3.27 & 15.14 \\
\hline 10.66 & 20.5 & 55.26 & 0.350 & 7.63 & 6.84 & 10.35 \\
\hline
\end{tabular}

Table 4. Predicted Results of Water Blocking

Note: $K_{o}, K_{o a}$ are the permeabilities to oil before and after water blocking damage,

respectively. $R_{s}$ is the permeability loss rate caused by water blocking damage, which can be calculated by $\left(K_{\mathrm{o}}-K_{\mathrm{oa}}\right) / K_{\mathrm{o}}$.

\subsection{Development of the grey neutral network model}

Water blocking may be regarded as a grey process containing known and unknown factors. Theory and practice have proven that the Grey GM $(0, n)$ prediction model is much better than the traditional MRA models for a complicated process. The GM $(0, n)$ model uses the accumulated data instead of the original data to establish the prediction model, which can weaken the randomness or eliminate the errors of the original data to some extent. However, the static Grey GM $(0, n)$ model is still a linear model that can not obtain accurate and satisfying result aiming at the prediction of water blocking. The problem can be solved by introducing the BP neural network with highly nonlinear and extrapolation into the Grey GM $(0, n)$ via referring to formation sensitivity prediction mentioned above. A grey neural network model used to predicting the formation damage induced by water blocking for formations with low-permeability has been established (Zhang, Z.H., 2001, Gruber, N.G., 1996).

Based on the test results, we assumed that the water blocking mainly depends on permeability to gas $K_{g}$, porosity $\varphi$, initial water saturation $S_{\mathrm{wi}}$ and oil /water interface tension $\sigma$. Firstly, the grey predicting model Grey GM $(0,5)$ was established to gain the accumulated data (see Appendix A), and then the gained data was input into the modified 
BP neural network model and thus the purpose of prediction was achieved. The predicted results using the grey neural network model are listed in Table 5. It can be seen that the grey neutral network model used to predict water blocking is reliable and has satisfactory accuracy and practicability. The evaluation criteria of water blocking damage are shown in Table 6.

\begin{tabular}{|c|c|c|c|c|}
\hline $\begin{array}{c}\boldsymbol{K}_{\mathrm{g}} \\
\mathbf{1 0 - 3} \mathbf{\mu m}_{\mathbf{~}}\end{array}$ & $\boldsymbol{R}_{\mathbf{s}} \%$ & Predicting $\boldsymbol{R}_{\mathbf{s}} \mathbf{\%}$ & $\begin{array}{c}\text { Experimental } \\
\text { results }\end{array}$ & Predicted results \\
\hline 11.96 & 50.00 & 49.6 & Intermediate & Intermediate \\
\hline 6.78 & 48.32 & 53.2 & Intermediate & Intermediate \\
\hline 19.86 & 16.12 & 14.1 & Weak & Weak \\
\hline 26.81 & 9.99 & 7.63 & Weak & Weak \\
\hline 9.22 & 19.34 & 22.8 & Weak & Intermediate-weak \\
\hline 4.67 & 15.14 & 19.7 & Weak & Weak \\
\hline 10.66 & 10.35 & 12.5 & Weak & Weak \\
\hline
\end{tabular}

Table 5. Predicted Results of Water Blocking

Note: Experimental results and Predicted results is the degree of water blocking damage.

\begin{tabular}{|c|c|c|c|c|c|}
\hline $\mathbf{R}_{\mathbf{s}}$ & $\leq \mathbf{2 0 \%}$ & $\mathbf{2 0 \% - 4 0 \%}$ & $\mathbf{4 0 \% - 6 0 \%}$ & $\mathbf{6 0 \% - 8 0 \%}$ & $>\mathbf{8 0} \%$ \\
\hline $\begin{array}{c}\text { Degree of } \\
\text { damage }\end{array}$ & Weak & $\begin{array}{c}\text { Intermediate- } \\
\text { weak }\end{array}$ & Intermediate & $\begin{array}{c}\text { Intermediate- } \\
\text { strong }\end{array}$ & Strong \\
\hline
\end{tabular}

Table 6. Evaluation Criteria of Water blocking Damage

\section{Protecting drilling fluid technique for the formations with low-porosity and low-permeability}

From the aspect of drilling fluids, the effective techniques of prevention for the formations with low-porosity and low-permeability have been proposed as follows: (1) The inhibition of drilling fluid should be enhanced in order to reduce the formation sensitivity; (2) Effecient surfactants should be optimized so as to reduce oil/water interfacial tension, and minimize formation damage induced by water blocking; (3) Adopt the technique of ideal packing compounding with film-forming to form quickly ultra-low permeable mud cake so as to minimize the filtrate of drilling fluids; (4) All kinds of treating agents used in drilling fluids should be compatible with formation rocks and fluid.

Take the typical formations with low-porosity and low-permeability located in Jilin Oilfield as an example. The effective porosity of the target formations is less than $13.3 \%$ and the average permeability is less than $18.39 \times 10^{-3} \mu^{2}$. According to the geological and formation characters in this area, the potassium chloride $(\mathrm{KCl})$ / polymer drilling fluid was selected. Based on the results of extensive tests, the basic formulation of drilling fluids was optimized as follows: $4 \%$ bentonite $+4.5 \% \mathrm{KCl}+0.3 \% \mathrm{KPAM}+1.5 \% \mathrm{NPAN}+1 \%$ anti-complex salt filtration control agent $+2 \%$ SMP- $1+1 \%$ sulfonated-asphalt (Formulation $1 \#$ ).

\subsection{Optimization of surfactants}

Adding proper surfactants in drilling fluids is able to minimize the oil/water interfacial tension, and then prevent or removal the water blocking timely. Five commonly used 
surfactants have been evaluated by measuring the contact angle in laboratory. From the Table 7 and Fig 4 we can see that the contact angles of OP-10 and ABSN are relatively small, which mean that the OP-10 and ABSN are strong in reducing the surface tension. However, OP-10 is water-soluble poorly. Hence the ABSN was recommended as the best waterblocking prevention agent.

\begin{tabular}{|c|c|c|c|c|c|c|}
\hline Solution & $\begin{array}{c}\text { Distilled } \\
\text { water }\end{array}$ & $\mathbf{0 . 4 \%}$ T-80 & $\mathbf{0 . 4 \% A B S}$ & $\mathbf{0 . 4} \%$ Span-80 & $\mathbf{0 . 4 \% O P - 1 0}$ & $\mathbf{0 . 4 \% A B S N}$ \\
\hline$\theta$ & 62.30 & 60.99 & 44.08 & 29.71 & 13.32 & 18.08 \\
\hline
\end{tabular}

Table 7. Contact angles for aqueous solutions of different kinds of surfactants (Ambient temperature, $20^{\circ} \mathrm{C}$ )
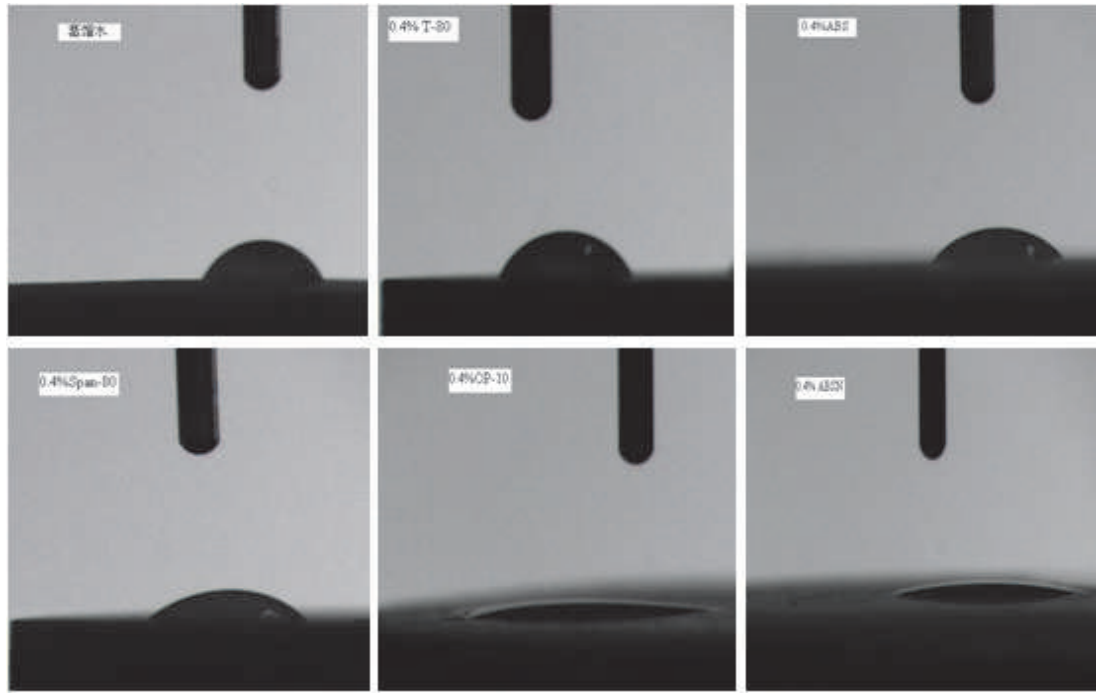

Fig. 4. The contact angles for aqueous solutions of different kinds of surfactants on waterwet rocks

It is shown from Fig.5 that ABSN exhibits excellent effects on reducing the interfacial tension and surface tension of filtrates with a very low concentration of its aqueous solution. The oil/water interfacial tension can be reduced to $0.65 \mathrm{mN} / \mathrm{m}$ when the concentration of ABSN is $0.2 \%$. Considering the lost amount of adsorption on cuttings, the recommended concentration of ABSN added in drilling fluids is $0.4 \%$.

\subsection{Optimization of Temporary Bridging Agents (TBA)}

The TBA in drilling fluids can quickly form thin and tough mud cake to prevent small particles and filtrates from invading formations. In this study, a mixed TBA has been selected according to the principle of Ideal Packing Theory (IPT) (Zhang, J.B., 2004). Adopting designing software developed by our research group, the optimized TBA (a combination of calcium carbonate with different particle size) was determined as below: $45 \mu \mathrm{m}(30 \%), 23 \mu \mathrm{m}(50 \%)$ and $13 \mu \mathrm{m}(20 \%)$. 

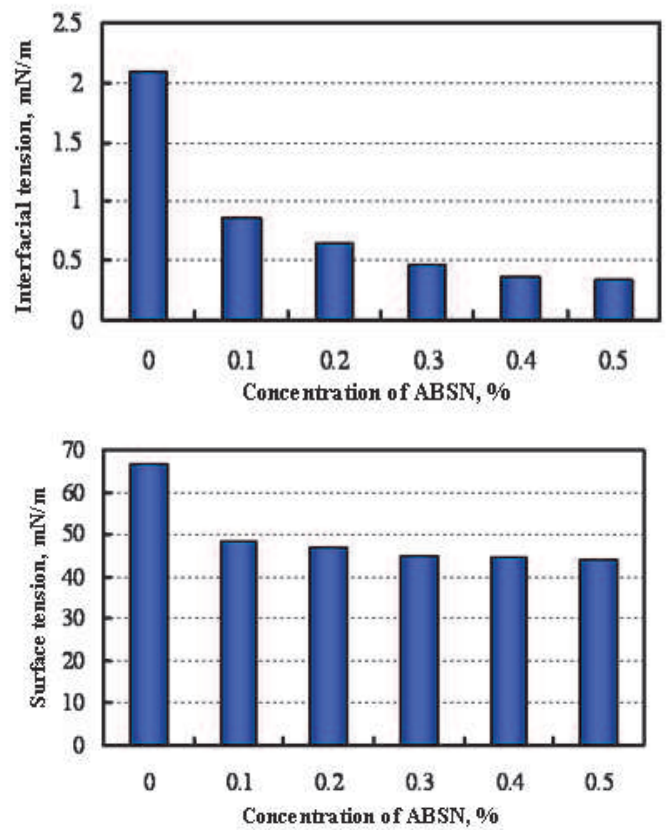

Fig. 5. Effect of ABSN concentration on o/w interfacial tension and surface tension of mud filtrates

The properties of drilling fluids after adding different amount of optimized TBA were measured as shown in Table 8. It is found that the addition of TBA has little impact on rheological parameters, but is helpful to reduce the filtration rate. Meanwhile, the spurt loss will decrease drastically, indicating that the presence of TBA in drilling fluids is beneficial to forming mud cake quickly. The relative amount of optimized TBA in drilling fluids is recommended as $2 \% \sim 3 \%$ that is different from the formations with high-permeability for which the relative amount of TBA should be $4 \% \sim 5 \%$.

\begin{tabular}{|c|c|c|c|c|c|c|c|}
\hline \multicolumn{2}{|c|}{ Fluid properties } & $\begin{array}{c}\rho \\
\mathrm{g} / \mathrm{cm}^{3}\end{array}$ & $\begin{array}{c}A V \\
\mathrm{mPa} \text { s }\end{array}$ & $\begin{array}{c}P V \\
\mathrm{mPa} \text { s }\end{array}$ & $\begin{array}{l}Y P \\
P a\end{array}$ & $\begin{array}{c}\mathrm{Gel} \\
\mathrm{Pa} / \mathrm{Pa}\end{array}$ & $\begin{array}{c}\text { API FL } \\
\text { ml }\end{array}$ \\
\hline \multirow{2}{*}{$1 \#$} & Room temperature & 1.14 & 33 & 22 & 12 & $1.5 / 3.0$ & 7.2 \\
\hline & $120^{\circ} \mathrm{C} / 16 \mathrm{~h}$ & 1.14 & 31 & 20 & 10 & $1.5 / 3.5$ & 8.0 \\
\hline \multirow{2}{*}{$1 \#+2 \%$ TBA } & Room temperature & 1.15 & 41 & 28 & 18 & $2.5 / 4.5$ & 6.4 \\
\hline & $120^{\circ} \mathrm{C} / 16 \mathrm{~h}$ & 1.15 & 38 & 32 & 15 & $4.0 / 5.0$ & 7.0 \\
\hline \multirow{2}{*}{$1 \#+3 \%$ TBA } & Room temperature & 1.16 & 50 & 38 & 20 & $3.5 / 6.5$ & 5.1 \\
\hline & $120^{\circ} \mathrm{C} / 16 \mathrm{~h}$ & 1.15 & 45 & 33 & 17 & $4.0 / 6.0$ & 4.8 \\
\hline \multirow{2}{*}{$1 \#+4 \% \mathrm{TBA}$} & Room temperature & 1.16 & 64 & 48 & 24 & $5.5 / 9.0$ & 4.8 \\
\hline & $120^{\circ} \mathrm{C} / 16 \mathrm{~h}$ & 1.16 & 58 & 44 & 21 & $4.5 / 8.0$ & 4.9 \\
\hline \multirow{2}{*}{$1 \#+5 \%$ TBA } & Room temperature & 1.18 & 72 & 52 & 27 & $5.0 / 9.5$ & 4.5 \\
\hline & $120^{\circ} \mathrm{C} / 16 \mathrm{~h}$ & 1.17 & 67 & 53 & 24 & $6.5 / 10$ & 4.8 \\
\hline
\end{tabular}

Table 8. Effect of the addition of TBA on properties of drilling fluids 


\subsection{Optimization of film-forming agents}

Two kinds of film-forming drilling fluid techniques have been developed in recent years (Tan C.P., 2002, Sun J.S., 2003, Yuan C., 2004, Sun J.S., 2005, Bai X.D., 2006). One is the semipermeable membrane, and its typical agent is JYW-1. By using the peculiar polymer agent, it can concentrate into micelle and thus form semi-permeable membrane at the rock surface so as to seal a wide range of the pore throat. The other is the isolating membrane, and its typical agent is CMJ-2. The polymer adsorbs, concentrates and forms into no permeable membrane at the rock surface, which is called isolating membrane that any solid and liquid phase can not transport.

Both kinds of film-forming techniques have their advantages and disadvantages. It takes 40 minutes to form the isolating membrane, while the filtrate of drilling fluid may invade into formations and induce damage during this period. In addition, it is difficult to form into the isolating membrane when the size of the pore throat is larger than $114 \mu \mathrm{m}$. The sealing capacity of the semi-permeable membrane is poor compared with the isolating membrane. However, the semi-permeable membrane can be formed quickly which usually takes only 1 to 3 minutes, and it can seal the large size of pore throat or the fracture (as large as $3 \mathrm{~mm}$ ) effectively.

Hence, given the characteristics of the two film-forming techniques, we have developed the double film-forming technique by compounding the two kinds of film-forming agents, which is synergistic. The mechanism of action is that the semi-permeable membrane is formed quickly and firstly, entering the large sizes of pore throat, and then the isolating membrane with no permeable is formed, supported by the wellbore wall and the semipermeable membrane. As for the formations with low-porosity and low-permeability, the proper concentrations of film-forming agents are $1.5 \% \mathrm{CMJ}-2+1 \% \mathrm{JYW}-1$, based on the extensive test results.

\subsection{The synergistic effect of the ideal packing and the film-forming techniques}

The TBA can block the large sizes of pore throat and fractures, while the double filmforming agents can form a sealing layer with zero permeability at the rock surface quickly. Compounding the techniques of Ideal Packing and Film-forming makes full use of the advantages of the two aspects and overcomes their own disadvantages, which can form a sealing layer with high pressure bearing capability at the rock surface, realizing the lowdamage or no-damage drilling. The schematic diagram is shown in Fig.6.

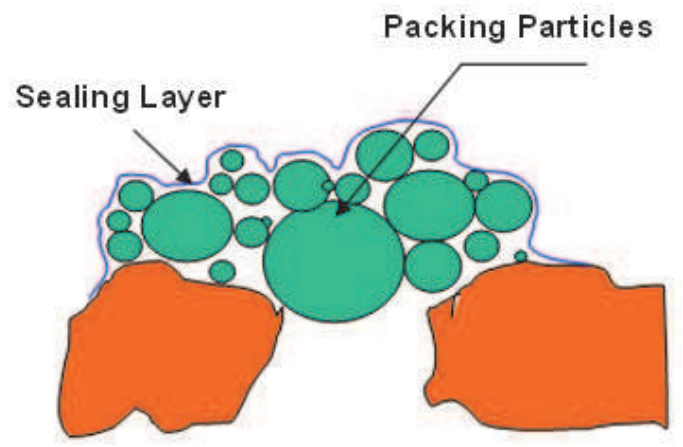

Fig. 6. Schematic diagram for the synergistic sealing layer 
Two core samples with similar permeability, A and B, were contaminated by distilled water $+1.5 \% \mathrm{CMJ}-2+1 \% \mathrm{JYW}-1$ (Formulation $2 \#$ ) and distilled water + 3\% IP-TBA + 1.5\%CMJ-2+ 1\%JYW-1 (Formulation 3\#), respectively. And then the Pressure Bearing Capacity Measurement Apparatus was used for the tests. As we can see from Fig.7, the pressure bearing capability of the core sample contaminated by $2 \#$ solution was improved to 3.5 $\mathrm{MPa}$, while the one contaminated by $3 \#$ solution was improved to $7.48 \mathrm{MPa}$. The experimental results proved that the synergistic effect of the ideal packing and the filmforming techniques is helpful to formation protection and wellbore stability, which can prevent or reduce effectively the filtrate of fluid, and decrease the transportation of pore pressure.

Pressure Bearing Capacity of Film-forming Agent

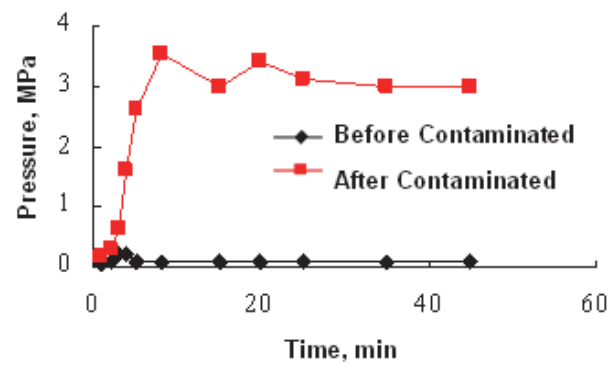

Pressure Bearing Capacity of Synergistic sealing layer

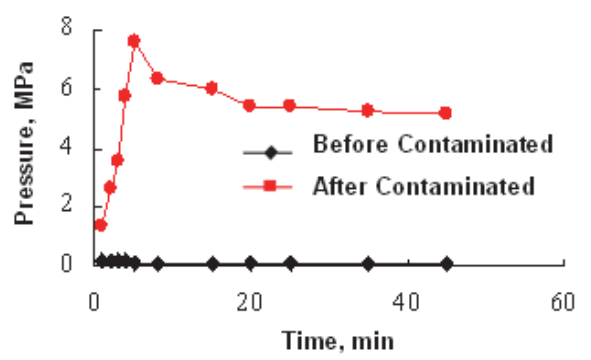

Fig. 7. The evaluation results of the pressure bearing capacity

Added 3\% TBA and 1.5\% CMJ-2 + 1\%JYW-1 into the 1\#, respectively. And then the dynamic filtrate of the two drilling fluids was tested so as to evaluate the synergistic sealing effect of the ideal packing and the film-forming techniques. The result was shown in Fig.8. We can see that the filtrate of drilling fluid adding the optimized film-forming agents and the TBA, was ultra-low and the initial filtrate was almost zero, which showed excellent formation protection, compared with the one adding the TBA only.

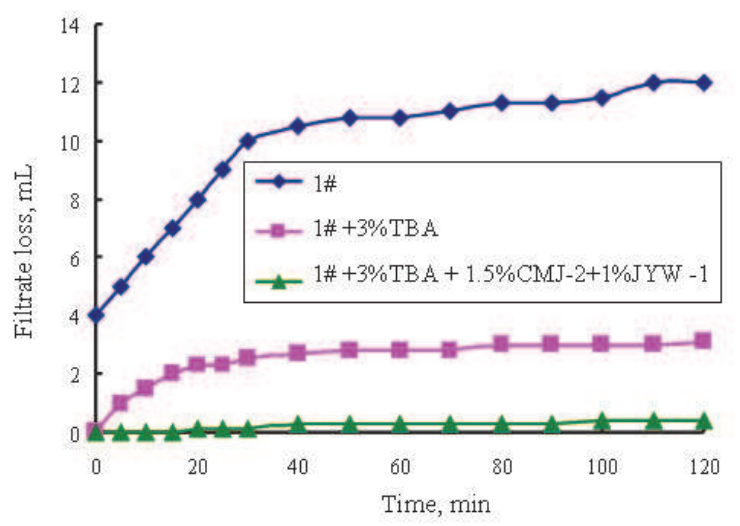

Fig. 8. Dynamic loss of drilling fluids with IP-TBA and film forming agents 


\section{Properties of newly developed drilling fluid}

Based on the optimization results, a novel low-damage drilling fluid has been developed. It is composed of polymers, water blocking preventing surfactants, TBA, film-forming agents and other additives. The typical formulation is as follow: $4 \%$ bentonite $+4.5 \% \mathrm{KCl}$ $+0.3 \% \mathrm{KPAM}+1.5 \% \mathrm{NPAN}+1 \%$ anti-complex salt filtration control agent $+2 \% \mathrm{SMP}-1+$ $1 \%$ sulfonated-asphalt $+0.4 \% \mathrm{ABSN}+3 \%$ TBA $+1.5 \% \mathrm{CMJ}-2+1 \% \mathrm{JYW}-1$ (Formulation $4 \#$ ).

The conventional properties of the novel drilling fluid were evaluated and the results are shown in Table 9. It can be seen that the novel drilling fluid has good rheological properties and the API filtration rates before or after rolling at $120^{\circ} \mathrm{C}$ for $16 \mathrm{~h}$ are less than $5 \mathrm{~mL}$, which can meet the requirements of drilling operations.

\begin{tabular}{|c|c|c|c|c|c|c|}
\hline Conditions & $\begin{array}{c}A \boldsymbol{V} \\
\mathbf{m P a} \mathbf{~ s}\end{array}$ & $\begin{array}{c}\boldsymbol{P V} \\
\mathbf{m P a} \mathbf{~ s}\end{array}$ & $\begin{array}{c}\mathbf{Y P} \\
\mathbf{P a}\end{array}$ & $\begin{array}{c}\mathbf{G e l} \\
\mathbf{P a} / \mathbf{P a}\end{array}$ & $\mathbf{p H}$ & $\begin{array}{c}\text { API FL } \\
\mathbf{m L}\end{array}$ \\
\hline $\begin{array}{c}\text { Room } \\
\text { temperature }\end{array}$ & 28 & 24 & 7.0 & $2.5 / 4.0$ & 8.0 & 4.0 \\
\hline $120^{\circ} \mathrm{C} / 16 \mathrm{~h}$ & 31 & 27 & 8.5 & $2 / 4.5$ & 8.0 & 3.6 \\
\hline
\end{tabular}

Table 9. Properties of the newly developed drilling fluid

The dynamic core flooding tests were conducted using the newly developed drilling fluid, compared with Formulation 1\#. The core samples were taken from a target formation with low-permeability in the Qian-231 well. The LH-2 HTHP dynamic core flooding apparatus manufactured by Lu Hai Co., Ltd was used for tests. The tests were performed at temperature of $90^{\circ} \mathrm{C}$, differential pressure of $3.5 \mathrm{MPa}$ and shear rate of $150 \mathrm{~s}^{-1}$. It is shown from Table 10 that the returned permeability of the core contaminated with the newly developed drilling fluid is $88.1 \%$, compared with the returned permeability of $77.4 \%$ contaminated by the former drilling fluid, indicating an exellent effectiveness of protecting the formations with low-porosity and low-permeability.

\begin{tabular}{|c|c|c|c|c|c|c|}
\hline $\begin{array}{c}\text { Core } \\
\text { No. }\end{array}$ & $\begin{array}{c}\text { Drilling } \\
\text { fluid System }\end{array}$ & $\boldsymbol{\varphi}, \boldsymbol{\%}$ & $\begin{array}{c}\boldsymbol{K}_{\mathrm{g}, \mathbf{1 0}^{-}} \\
{ }^{3} \mathbf{\mu m}^{\mathbf{2}}\end{array}$ & $\begin{array}{c}\boldsymbol{K}_{\mathbf{o}}, \mathbf{1 0}^{-} \\
{ }^{3} \mathbf{\mu m}^{\mathbf{2}}\end{array}$ & $\begin{array}{c}\boldsymbol{K}_{\mathbf{o a}}, \mathbf{1 0}^{-} \\
{ }^{3} \boldsymbol{\mu m}^{2}\end{array}$ & $\begin{array}{c}\text { Returned } \\
\text { permeability, } \%\end{array}$ \\
\hline 1 & $1 \#$ & 10.45 & 7.93 & 2.75 & 2.13 & 77.4 \\
\hline 2 & $4 \#$ & 10.08 & 6.56 & 2.15 & 1.90 & 88.1 \\
\hline
\end{tabular}

Table 10. Results of the returned permeability for cores

\section{Conclusions}

The main mechanisms of damage for the formations with low-porosity and lowpermeability are usually water-sensitivity and water blocking. The extent of water blocking damage is related to various influencing factors such as permeability, initial water saturation, porosity, and oil/water interfacial tension.

The Artificial neural network (ANN) model and software have been developed successfully to predict sensitivities of formations. Extensive applications show that more than $85 \%$ of predicted results are in agreement with the measured results. The grey neutral network model takes the advantage of grey static models and the non-linear of neural network, and can be used to predict water blocking with more precise results.

Some surfactants or alcohols are helpful to minimize surface tension of filtrates and oil/water interfacial tension, and reduce the capillary resistance and prevent water blocking 
damage. Compounding the techniques of Ideal Packing and Film-forming makes full use of the advantages of the two aspects and overcomes their own disadvantages, which can form a sealing layer with high pressure bearing capability at the rock surface, realizing the lowdamage or no-damage drilling. The newly developed drilling fluid is suitable for protecting the typical reservoirs with low-permeability and has excellent performance. The returned permeability of the contaminated with this drilling fluid is higher than $88 \%$.

\section{Appendix A-establishment of GM (0 N)}

\subsection{Assumption}

$X_{1}$-Damage ratio caused by water-blocking, \%; $X_{2}$ - Gas permeability, $10^{-3} \mu \mathrm{m}^{2}$; $\boldsymbol{X}_{3}$ - Initial saturation, $\% ; \boldsymbol{X}_{4}$ - Oil / water interfacial tension, $\mathrm{mN} / \mathrm{m} ; \boldsymbol{X}_{5}$ - Porosity, $\%$. Establish the $\operatorname{GM}(0,5)$ related to $X_{1}$ as following equation:

$$
X_{1}^{(1)}(i)=b_{1} X_{2}^{(1)}(i)+b_{2} X_{3}^{(1)}(i)+b_{3} X_{4}^{(1)}(i)+b_{4} X_{5}^{(1)}(i)+a
$$

The parameter list is yet to be determined:

$$
\hat{b}=\left[b_{1}, b_{2}, b_{3}, b_{4}, a\right]
$$

Data matrix is formed as follows:

$$
B=\left[\begin{array}{cccc}
X_{2}^{(1)}(2), & X_{3}^{(1)}(2), & X_{4}^{(1)}(2), & 1 \\
X_{2}^{(1)}(3), & X_{3}^{(1)}(3), & X_{4}^{(1)}(3), & 1 \\
\cdots & \cdots & \cdots \\
X_{2}^{(1)}(n), & X_{3}^{(1)}(n), & X_{4}^{(1)}(n), & 1
\end{array}\right]
$$

$Y_{N}=\left[X_{1}^{(1)}(2), X_{1}^{(1)}(3), \cdots, X_{1}^{(1)}(n-1), X_{1}^{(1)}(n)\right]^{T}(n$, the number of samples $)$

\subsection{The calculative process}

The original data is listed below:

\begin{tabular}{|c|c|c|c|c|c|c|c|}
\hline Original data & $\boldsymbol{k}=\mathbf{1}$ & $\boldsymbol{k}=\mathbf{2}$ & $\boldsymbol{k}=\mathbf{3}$ & $\boldsymbol{k}=\mathbf{4}$ & $\boldsymbol{k}=\mathbf{5}$ & $\boldsymbol{k}=\mathbf{6}$ & $\boldsymbol{k}=\mathbf{7}$ \\
\hline$X_{1^{(0)}}(k)$ & 50 & 48.32 & 16.12 & 9.99 & 19.34 & 15.14 & 10.35 \\
\hline$X_{2}^{(0)}(k)$ & 11.96 & 6.78 & 19.86 & 26.81 & 9.22 & 4.67 & 10.66 \\
\hline$X_{3}^{(0)}(k)$ & 49.29 & 14.75 & 65.84 & 40.02 & 51.79 & 38.95 & 55.26 \\
\hline$X_{4}(0)(k)$ & 2.081 & 2.081 & 0.868 & 0.652 & 0.469 & 0.36 & 0.35 \\
\hline$X_{5^{(0)}}(k)$ & 16.8 & 9.34 & 9.16 & 14.8 & 22.2 & 16 & 20.5 \\
\hline
\end{tabular}

$X_{i}^{(1)}(k) \quad(i=1,2,3,4 \quad k=1,2, \cdots, 6,7)$ is the one time accumulating value of $X_{i}^{(0)}(k)$.

According to

$$
X_{i}^{(1)}(k)=\sum_{j=1}^{k} X_{i}^{(o)}(j)
$$




\begin{tabular}{|c|c|c|c|c|c|c|c|}
\hline Original data & $\boldsymbol{k}=\mathbf{1}$ & $\boldsymbol{k}=\mathbf{2}$ & $\boldsymbol{k}=\mathbf{3}$ & $\boldsymbol{k}=\mathbf{4}$ & $\boldsymbol{k}=\mathbf{5}$ & $\boldsymbol{k}=\mathbf{6}$ & $\boldsymbol{k}=\mathbf{7}$ \\
\hline$X_{1^{(0)}}(k)$ & 50 & 98.32 & 114.44 & 124.43 & 143.77 & 158.91 & 169.26 \\
\hline$X_{2^{(0)}}(k)$ & 11.96 & 18.74 & 38.6 & 65.41 & 74.63 & 79.3 & 89.96 \\
\hline$X_{3}^{(0)}(k)$ & 49.29 & 64.04 & 129.88 & 169.9 & 221.69 & 260.64 & 315.9 \\
\hline$X_{4}^{(0)}(k)$ & 2.081 & 4.162 & 5.03 & 5.682 & 6.151 & 6.511 & 6.861 \\
\hline$X_{5}^{(0)}(k)$ & 16.8 & 26.14 & 35.3 & 50.1 & 72.3 & 88.3 & 108.8 \\
\hline
\end{tabular}

Then the data matrix is gained as follows:

$$
\begin{aligned}
Y_{N} & =\left[X_{1}^{(1)}(2), X_{1}^{(1)}(3), \cdots, X_{1}^{(1)}(6), X_{1}^{(1)}(7)\right] T^{\mathrm{T}} \\
= & {[98.32,114.44,124.43,143.77,158.91,169.26] } \\
B & =\left[\begin{array}{ccccc}
18.74 & 64.04 & 4.162 & 26.14 & 1 \\
38.60 & 129.88 & 5.030 & 35.3 & 1 \\
65.41 & 169.90 & 5.682 & 50.1 & 1 \\
74.63 & 221.69 & 6.151 & 72.3 & 1 \\
79.30 & 260.64 & 6.511 & 88.3 & 1 \\
89.96 & 315.90 & 6.861 & 108.8 & 1
\end{array}\right]
\end{aligned}
$$

The relevant parameters are calculated:

$$
\hat{b}=\left[B^{T} B\right]^{-1} B^{T} Y_{N}=[-0.7959,-0.2137,45.3895,0.7132,-80.6178]^{T}
$$

Then $b_{1}=-0.7959, b_{2}=-0.2137, b_{3}=45.3895, b_{4}=0.7132, a=-80.6178$

The final equation $G(0,5)$ is gained as follows:

$$
\begin{gathered}
\hat{X}_{1}^{(1)}(k)=-0.7959 X_{2}^{(1)}(k)-0.2137 X_{3}^{(1)}(k)+45.3895 X_{4}^{(1)}(k)+0.7132 X_{5}^{(1)}(k)-80.6178 \\
\hat{X}_{1}^{(0)}(k)=\hat{X}_{1}^{(1)}(k)-\hat{X}_{1}^{(1)}(k-1) \quad(k \geq 2)
\end{gathered}
$$

The original data is invalid after the accumulation above. Then the value of number $k+1$ must be calculated on the basic of the independent variables $k$, generated by the $\operatorname{GM}(0,5)$.

\section{Acknowledgements}

We gratefully acknowledge the financial support for the research project provided by the China National Natural Science Foundation (Project No.50974129).

\section{References}

Bai X.D., Pu X.L., Evolution of membrane forming technology of water-based mud [J]. Atural Gas Industry, 2006,26(08):75-77.

Bennion, D. B., "An Overview of Formation Damage Mechanisms Causing a Reduction in the Productivity and Injectivity of Oil and Gas Producing Formations", Journal of Canadian Petroleum Technology, Volume 41, No.11 Nov. 10-15 2002 
Bennion, D. B., Thomas, F.B., and Ma,T.,"Formation Damage Processed Reducing Productivity of Low Permeability Gas Reservoirs, " SPE 60325, SPE Rocky Mountain Regional Low Permeability Reservoirs Symposium, Denver, Mar.12-15,2000

Brian, D., William, D.W., "Maximizing Economic Return by Minimizing or Preventing Aqueous Phase Trapping During Completion and Stimulation Operations" SPE 90170, presented at the SPE Annual Technical Conference and Exhibition held in Houston,Texas, Sep. 26-29,2004.

Erwom, M D., Riersom, C.R., and Bennion, D.B., "Brine Inhibition Damage in the Colville River Field, Alasla, " SPE 84320, SPE Annual Technical Conference, Denver, Oct. 5-8,2003

Geng J.J., Yan J.N., et al. Mechanisms and prevention of damage for formations with lowporosity and low-permeability [R]. SPE130961, 2010.

Gruber, N.G., "Water Block Effects in Low Permeability Gas Reservoirs", presented at the 47th Annual Technical Meeting of The Petroleum Society in Calgary, Alberta, June 10-12,1996

Kalam, M.Z., Al-Alami, S.M., and Al-Mukheini, M., "Assesment of Formation Damage Using Artificial Neural Networks", paper SPE 31100 presented at the 1996 Formation Damage Symposium, Lafayetter,Feb.14-15

Nikravesh, M., Kovscek, A.R., Johnston, R.M., and Patzek, T.W., "Prediction of Formation Damage During Fluid Injection into Fractured, Low Permeability Reservoirs via Neural Networks", paper SPE 31103 presented at the 1996 Formation Damage Symposium, Lafayetter,Feb.14-15

Shu Y., Yan J.N., Xiong C.M., et al. Mechanism and preventive techniques of fluid-block damage for tight sandstone condensate gas reservoirs with low-permeabilit[J]. Petroleum Exploration and Development, 2009,36(5): 628-634.

Sun J.S., Wang S.G., Zhang Y., et al. Study on membrane generating technology of waterbased drilling fluid[J] Driling Fluid and Completion Fluid, 2003, 20(06):6-10.

Sun J.S., Tang J.P.,Zhang B.,,Wang S.G., et al. Study on ultra-low permeability drilling/completion fluid[J]. Driling Fluid and Completion Fluid, 2005, (01):1-4.

Tan C P, Mody F K, Tare V A. Novel high membrane efficiency water-based drilling fluids for alleviating problems in troublesome shale formations[R]. SPE77192, 2002.

Tan C P, Mody F K, Tare V A. Development and laboratory verification of high membrane efficiency water-based drilling fluids with oil-based drilling fluid-like performance in shale stabilization[R].SPE78159, 2002.

Yuan C., Sun J.S., Wang P.Q., et al. Development of CMJ-1-a high temperature filmforming fluid loss additive and the properties[J]. Petroleum Drilling Techniques, 2004, 32(2):30-32.

Zuluaga,E., "Prediction of Permeability Reduction by External Particle Invasion Using Artificial Neural Networks and Fuzzy Models",presented at the Petroleum Society's Canadian International Petroleum Conference 2000, Calgary, Alberta, June 4-8,2000

Zhang, Z.H., Yan,J.N., Wu, Y.M., The Model of gray neural network for predicting water blocking damage of low permeability sandstone reservoirs[J]. Drilling \& Production Technology, 2001, 24 (1): 38-40

Zhang, J.B., Yan J.N., New theory and method for optimizing the particle size distribution of bridging agents in drilling fluids[J]. Acta Petrolei Sinica, 2004, 25 (6):88-91

Zhang H.X, Yan J.N., Shu Yong, Xue Yuzhi. High-performance polyalcohol drilling fluid applied to protection of ultra-deep reservoir with low permeability[J]. Acta Petrolei Sinica, 2010,31(1): 129-133 


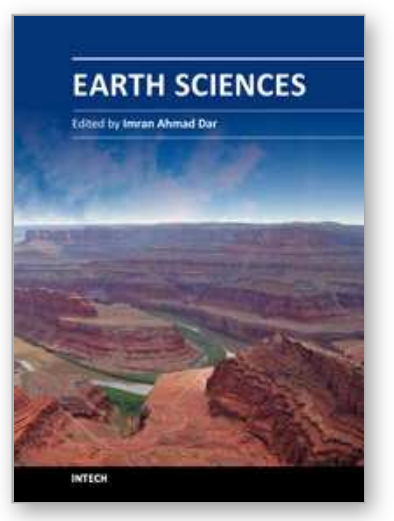

\author{
Earth Sciences \\ Edited by Dr. Imran Ahmad Dar
}

ISBN 978-953-307-861-8

Hard cover, 648 pages

Publisher InTech

Published online 03, February, 2012

Published in print edition February, 2012

The studies of Earth's history and of the physical and chemical properties of the substances that make up our planet, are of great significance to our understanding both of its past and its future. The geological and other environmental processes on Earth and the composition of the planet are of vital importance in locating and harnessing its resources. This book is primarily written for research scholars, geologists, civil engineers, mining engineers, and environmentalists. Hopefully the text will be used by students, and it will continue to be of value to them throughout their subsequent professional and research careers. This does not mean to infer that the book was written solely or mainly with the student in mind. Indeed from the point of view of the researcher in Earth and Environmental Science it could be argued that this text contains more detail than he will require in his initial studies or research.

\title{
How to reference
}

In order to correctly reference this scholarly work, feel free to copy and paste the following:

Jienian Yan and Jiaojiao Geng (2012). Mechanisms and Effective Prevention of Damage for Formations with Low-Porosity and Low-Permeability, Earth Sciences, Dr. Imran Ahmad Dar (Ed.), ISBN: 978-953-307-861-8, InTech, Available from: http://www.intechopen.com/books/earth-sciences/mechanisms-and-effectiveprevention-of-damage-for-formations-with-low-porosity-and-low-permeability

\section{INTECH}

open science | open minds

\author{
InTech Europe \\ University Campus STeP Ri \\ Slavka Krautzeka 83/A \\ 51000 Rijeka, Croatia \\ Phone: +385 (51) 770447 \\ Fax: +385 (51) 686166 \\ www.intechopen.com
}

\author{
InTech China \\ Unit 405, Office Block, Hotel Equatorial Shanghai \\ No.65, Yan An Road (West), Shanghai, 200040, China \\ 中国上海市延安西路65号上海国际贵都大饭店办公楼405单元 \\ Phone: +86-21-62489820 \\ Fax: $+86-21-62489821$
}


(C) 2012 The Author(s). Licensee IntechOpen. This is an open access article distributed under the terms of the Creative Commons Attribution 3.0 License, which permits unrestricted use, distribution, and reproduction in any medium, provided the original work is properly cited. 